\title{
Inhibition of Ouabain-sensitive ATPase by the Saliva of Patients with Cystic Fibrosis of the Pancreas
}

\author{
C. H. COLE ${ }^{(25)}$ AND G. SELLA \\ Department of Medicine, Roval Victoria Hospital, Montreal, Quebec, Canada
}

\begin{abstract}
Extract
A study has been made of the effect of saliva from children with cystic fibrosis of the pancreas (CFP) on various components of the ATP hydrolyzing enzyme system. The ouabain-sensitive ATPase activity of erythrocyte membranes prepared from intact erythrocytes preincubated with CFP saliva was $35 \pm 4 \mathrm{nmol} P_{i} / \mathrm{mg}$ dry wt membrane suspension/hr, compared with $48 \pm 7 \mathbf{n m o l} P_{\mathrm{i}} / \mathbf{m g}$ dry wt membrane suspension/hr when the erythrocytes were preincubated with control saliva. A calcium-activated component of ATPase was decreased from $202 \pm 30 \mathrm{nmol} P_{\mathrm{i}} / \mathrm{mg}$ dry wt membrane suspension/hr in erythrocytes preincubated with control saliva, to $151 \pm$ $17 \mathrm{nmol} \mathrm{P}_{\mathrm{i}} / \mathrm{mg}$ dry wt membrane suspension/hr when the incubation was carried out with CFP saliva.

In a second series of experiments, ultrafiltered saliva was added directly to an ATPase assay. The saliva from children with CFP. brought about a mean decrease in ouabain-sensitive ATPase of $16 \%$ compared with control saliva.
\end{abstract}

\section{Speculation}

Inhibition of active cation transport at various sites in the body is one of the hallmarks of CFP. Electrolyte abnormalities in the saliva of patients with CFP may result from the action of an ATPase inhibitory factor in the saliva which inhibits various components of ATPase in the ducts of the salivary glands. Such a factor could be similar or identical with the ciliotoxic factor identified by other investigators in the serum and saliva of patients with CFP.

Children with CFP have been demonstrated to have a higher than normal concentration of sodium in mixed saliva (19). The reasons for this elevation of salivary sodium have not been defined. Mangos et al. (14) have shown that retrograde perfusion of the rat parotid duct with CFP saliva resulted in a decrease in the rate of sodium reabsorption in the parotid duct, but were unable to demonstrate an effect of CFP saliva on ( $\mathrm{Na}, \mathrm{K}$ )-ATPase from various tissues.

The presumed decrease in the rate of sodium reabsorption in the salivary ducts of children with CFP represents only one aspect of a widespread disturbance in active membrane cation transport in children with this disease $(9,10,17)$. We have reported a factor in the plasma of children with CFP which inhibits a ouabain-sensitive, sodium-potassium-activated component of ATPase from normal erythrocyte membranes (4). The action of a similar factor in the saliva of children with CFP could have been obscured in previous studies by the relatively high concentration of phosphorous normally present in the saliva. In this paper, we report the results of two series of experiments designed to study the effect of CFP saliva on an ATPase assay system.

\section{METHODS}

The patients with CFP used in this study were attending the outpatient clinic of the Montreal Children's Hospital. They ranged in age from 5 to 15 years, were about equally divided as to sex, and had Shwachman scores ranging from 33 91. Mixed saliva was obtained by asking each child to rinse his mouth with water, and then giving him a piece of laboratory parafilm to chew. No effort was made to record or control the salivary flow rate, or the time since the last meal. Fifteen milliliters of saliva were collected in a glass vial, centrifuged momentarily at $7,500 \times g$ to remove particulate matter, and then treated as outlined below. A similarly reated control saliva sample, collected from laboratory personnel, was included in each experiment.

\section{PREINCUBATION EXPERIMENTS}

The osmolarity of the saliva was measured with an Advanced Digimatic osmometer. Sufficient $1 \mathrm{M} \mathrm{NaCl}$ was added to the saliva to make it iso-osmotic, and the effect of this saliva on the ATPase activity of intact erythrocytes was determined by incubating $5 \mathrm{ml}$ saline-washed erythrocytes from normal control subjects with $7.5 \mathrm{ml}$ saliva. The incubating solution contained, in addition to the saliva, $100 \mathrm{mg}$ glucose, $0.5 \mathrm{ml} 1 \mathrm{M}$ sodium phosphate buffer (pH 7.45), 250,000 units penicillin $\mathrm{G}$, and $50 \mathrm{mg}$ streptomycin sulfate. The final hematocrit of the erythrocyte suspension was $54 \%$. After an arbitrarily chosen incubation period of $18 \mathrm{hr}$ at $37^{\circ}$ in a shaking water bath, the erythrocytes were washed free of saliva, and fragmented erythrocyte "ghosts" were prepared by an osmotic hemolysis technique (4).

ATPase activity of the ghosts was assayed in a basic medium that contained $75 \mathrm{mM} \mathrm{Na}, 25 \mathrm{mM} \mathrm{K}, 25 \mathrm{mM}$ Tris (pH 7.45), $1 \mathrm{mM}$ $\mathrm{Mg}$, and $1 \mathrm{mM}$ ATP. ATPase activity, determined by the amount of $P_{i}$ released, was related to the dry weight of the membrane suspension, measured on an electrobalance after $24 \mathrm{hr}$ of drying in a vacuum oven. Phosphorus was determined by an autoanalyzer modification of the Lowry-Lopez technique (13).

The Na-K-activated, ouabain-sensitive component of ATPase was determined by subtracting the activity in the presence of $1 \mathrm{mM}$ ouabain from the full activity measured in the above medium. A calcium-activated component of ATPase was determined by adding $0.15 \mathrm{mM}$ calcium and $0.1 \mathrm{mM}$ EGTA to the basic medium. Calcium-activated ATPase was then defined as the difference in ATPase activity in the presence and absence of calcium.

All determinations were done in duplicate, and appropriate boiled membrane blanks were included with each experiment.

\section{FILTRATION EXPERIMENTS}

Saliva was obtained as outlined above. Saliva $(10 \mathrm{ml})$ was added to a Millipore ultrafiltration cell containing a Pellicon ultrafiltration membrane (type PSAC) with a nominal molecular weight cutoff of 1,000 . Ultrafiltration with a gas pressure of 10 p.s.i. was carried out until the volume of saliva had been reduced to approximately $1 \mathrm{ml}$. Water $(9 \mathrm{ml})$ was added, and the procedure repeated. After the third wash, the phosphorus concentration of the saliva, reconstituted to its original volume, was measured. If this was greater than $0.2 \mathrm{mM}$, an additional wash was performed. At this point,the sodium and potassium concentration was less than $1 \mathrm{mM}$, and the calcium less than $0.05 \mathrm{mM}$. One milliliter of this saliva was then added directly to an ATPase assay medium. Erythrocyte membranes from normal controls, prepared by our 
usual osmotic hemolysis technique, were used as a source of ATPase. Each tube in the assay contained, in addition to $1 \mathrm{ml}$ saliva, $0.5 \mathrm{ml}$ erythrocyte membrane suspension and $1.0 \mathrm{ml}$ of the basic incubation medium described above. The assay was performed in the presence and absence of $1 \mathrm{mM}$ ouabain, and ouabain-sensitive ATPase activity was defined as outlined above.

\section{RESULTS}

The concentration of phosphorus in mixed saliva of children with CFP was found to range from 3 to $8 \mathrm{mM}$. In initial experiments, it was found that this concentration of phosphorus, when added directly to an ATPase assay, made it difficult to detect the relatively small amount of phosphorus released from the substrate during the course of the assay.

In order to circumvent this problem, two series of experiments were designed. In the first series of experiments, intact erythrocytes were preincubated for $18 \mathrm{hr}$ in CFP saliva. They were then washed free of saliva, hemolyzed, and the broken membranes were assayed for ATPase. In the second series of experiments, saliva was washed with an ultrafiltration membrane to reduce the phosphorus content, and the saliva was then added directly to an ATPase assay system.

\section{PREINCUBATION EXPERIMENTS}

Mixed saliva was obtained from children with CFP and from normal healthy controls subjects. Intact erythrocytes were incubated in this saliva for $18 \mathrm{hr}$ and then assayed for ATPase activity, as outlined under Methods. Concomitantly, the ATPase activity of the same erythrocytes incubated in the saliva of a normal control was tested. Two patients were paired with one control in seven of the eight experiments. The ATPase activity in the presence of maximally activating concentrations of $\mathrm{Na}, \mathrm{K}$, and $\mathrm{Mg}$ was less after preincubation with CFP saliva than it was after preincubation with control saliva in 14 of the 15 saliva samples tested, as shown in Table 1 .

The mean activity of the erythrocytes incubated in control saliva was $81 \pm 15 \mathrm{nmol} \mathrm{P}_{\mathrm{i}} / \mathrm{mg}$ dry wt membrane suspension $/ \mathrm{hr}$. The mean activity of the same erythrocytes incubated in CFP saliva was $55 \pm 8 \mathrm{nmol} P_{\mathrm{i}} / \mathrm{mg}$ dry wt membrane suspension $/ \mathrm{hr}$.

The component of ATPase which has been most closely implicated in active $\mathrm{Na}$ transport is activated by sodium and potassium and inhibited by the cardiac glycoside ouabain. The effect of preincubation of erythrocytes with CFP saliva on this component of ATPase is also shown in Table 1. The mean ouabain-sensitive ATPase activity of the erythrocytes preincubated with CFP saliva was $35 \pm 4 \mathrm{nmol} \mathrm{P}_{\mathrm{i}} / \mathrm{mg}$ dry wt membrane suspension $/ \mathrm{hr}$, compared with $48 \pm 7 \mathrm{nmol} \mathrm{P}_{\mathrm{i}} / \mathrm{mg}$ dry wt membrane suspension/hr after preincubation with control saliva. The mean ratio of ouabain-sensitive ATPase after preincubation with CFP saliva to ouabain-sensitive ATPase after preincubation with control saliva was $0.74 \pm 0.08$, indicating a mean decrease of ouabain sensitive ATPase of $26 \%$.

Schatzman and Vincenzi (15) have described a calciumactivated component of ATPase which may be involved in active calcium transport. The effect of CFP saliva on this component of ATPase was also assessed. Preincubation of erythrocytes with CFP saliva also resulted in a decrease in the activity of this component of ATPase. The mean Ca-activated ATPase activity in the presence of CFP saliva was $151 \pm 17 \mathrm{nmol} \mathrm{P}_{\mathrm{i}} / \mathrm{mg} /$ dry wt membrane suspension/hr, as compared with $202 \pm 30 \mathrm{nmol} \mathrm{P} / \mathrm{mg}$ dry wt membrane suspension/hr in the presence of control saliva.

Marked variability was noted in all components of ATPase from experiment to experiment. Similar variability has been noted in previous series of experiments (5). Other investigators have drawn attention to differences in membrane preparation as a source of variability in ATPase activity (8), and the assay itself has a certain degree of inherent variability. In order to control these problems, the principle of strict pairing of patient and control samples was

Table 1. ATPase activity of erythrocytes preincubated with control and cistic fibrosis of the pancreas saliva

\begin{tabular}{|c|c|c|c|c|c|c|}
\hline \multicolumn{4}{|c|}{$\begin{array}{l}\text { Preincubation with patient saliva, nmol } \mathrm{P}_{\mathrm{i}} \text { released } / \mathrm{mg} \\
\text { dry wt membrane suspension } / \mathrm{hr}\end{array}$} & \multicolumn{3}{|c|}{$\begin{array}{l}\text { Preincubation with control saliva, nmol } \\
\mathrm{P}_{1} \text { released } / \mathrm{mg} \text { dry wt membrane suspension } / \mathrm{hr}\end{array}$} \\
\hline $\begin{array}{l}\text { Patient } \\
\text { identification }\end{array}$ & $\mathrm{Na}^{+}, \mathrm{K}^{+}, \mathrm{Mg}^{++}$ & $\begin{array}{l}\text { Ouabain } \\
\text { sensitive }\end{array}$ & $\begin{array}{l}\text { Calcium } \\
\text { activated }\end{array}$ & $\mathrm{Na}^{+}, \mathrm{K}^{+}, \mathrm{Mg}^{++}$ & $\begin{array}{l}\text { Ouabain } \\
\text { sensitive activated }\end{array}$ & $\begin{array}{l}\text { Calcium } \\
\text { activated }\end{array}$ \\
\hline$L S$ & 95 & 50 & 126 & 131 & 57 & 218 \\
\hline$P B$ & 121 & 55 & 203 & & & \\
\hline$T K$ & 72 & 28 & 153 & 133 & 67 & 203 \\
\hline$S J E$ & 19 & 12 & 32 & & & \\
\hline$C M$ & 74 & 49 & 223 & 76 & 48 & 214 \\
\hline$S L O$ & 44 & 30 & 136 & & & \\
\hline$D E L$ & 36 & 29 & 137 & 66 & 53 & 188 \\
\hline$D A L$ & 22 & 22 & 59 & & & \\
\hline$L B$ & 23 & 23 & 127 & 39 & 29 & 116 \\
\hline$S J A$ & 52 & 35 & 175 & & & \\
\hline$S L$ & 82 & 56 & 238 & 124 & 73 & 367 \\
\hline$S Y L$ & 79 & 64 & 271 & & & \\
\hline$L B$ & 54 & 39 & 174 & 55 & 40 & 221 \\
\hline$L F$ & 37 & 24 & 140 & & & \\
\hline$L T$ & 13 & 10 & 72 & 24 & 19 & 89 \\
\hline $\begin{array}{l}\bar{\chi} \\
\pm \mathrm{SEM}\end{array}$ & $55 \pm 8$ & $35 \pm 4$ & $151 \pm 17$ & $81 \pm 15$ & $48 \pm 7$ & $202 \pm 30$ \\
\hline
\end{tabular}


adhered to. Two aliquots of a single sample of erythrocytes were incubated with patient and control saliva, and all subsequent steps of membrane preparation and assay were carried out in a tightly coupled fashion. Statistical analysis of the data was carried out with a two tailed paired value Student's $t$ test. In cases where two CFP saliva samples were compared with one control sample, the ATPase activity in the presence of the two CFP saliva samples was averaged. When analyzed in this fashion, the effect of CFP saliva on all three components of ATPase studied was statistically significant with a $P$ value less than 0.05 .

Shwachman scores (15) of the patients used in this series of experiments ranged from 33 to 91 . There was no overall correlation between Shwachman scores in these patients and the decrease in any component of ATPase $(r<0.44 ; P>0.05)$. The patients were divided into deciles on the basis of Shwachman score, and again no correlation could be demonstrated between clinical severity of the disease and decrease in ATPase. However, as shown in Table 2 , in the seven experiments in which two patients were paired with one control, the patient with the lowest Shwachman score tended to have saliva which produced the most marked decrease in ATPase.

\section{FILTRATION EXPERIMENTS}

In a second series of experiments, CFP saliva was filtered through a Pellicon ultrafiltration membrane, as outlined under Methods. Each assay was performed with a sample of CFP saliva, and with a sample of similarly treated control saliva. The results are shown in Table 3. There was no significant effect of CFP saliva treated in this manner on total ATPase activity. The mean activity in the presence of CFP saliva was $122 \pm 26 \mathrm{nmol} \mathrm{P}_{\mathrm{i}} / \mathrm{mg}$ dry wt membrane suspension/hr, compared with $132 \pm 27 \mathrm{nmol}$ $\mathrm{P}_{\mathrm{i}} / \mathrm{mg}$ dry wt membrane suspension/hr in the presence of control saliva. However, when the ATPase activity was partitioned into ouabain-sensitive and ouabain-insensitive components, a significant effect of CFP saliva on the ouabain-sensitive component of ATPase was observed. The mean ratio of ouabain-sensitive ATPase activity in the presence of CFP saliva to ouabain-sensitive ATPase activity in the presence of control saliva was 0.84 , indicating a mean decrease in ouabain-sensitive ATPase activity of

Tuble 2. Percentage of change in ATPase activitl after preincubation with cistic fibrosis of the pancreas saliva relative to activity of same erithrocites preincubated in control saliva

\begin{tabular}{lcccc}
\hline $\begin{array}{l}\text { Patient } \\
\text { identi- } \\
\text { fication }\end{array}$ & $\begin{array}{c}\text { Schwachman } \\
\text { score }\end{array}$ & $\mathrm{Na}^{+}, \mathrm{K}^{+}, \mathrm{Mg}^{++}$ & $\begin{array}{c}\text { Ouabain } \\
\text { sensitive }\end{array}$ & $\begin{array}{c}\text { Calcium } \\
\text { activated }\end{array}$ \\
\hline$L S$ & 45 & -27 & -12 & -42 \\
$P B$ & 52 & -8 & -4 & -7 \\
$T K$ & 81 & -46 & -58 & -24 \\
$S J E$ & 86 & -86 & -82 & -84 \\
& & & & \\
$C M$ & 91 & -3 & +2 & +4 \\
$S L O$ & 40 & -42 & -37 & -36 \\
$D E L$ & 80 & -45 & -45 & -27 \\
$D A L$ & 73 & -66 & -58 & -69 \\
$L B$ & 80 & -41 & -21 & +9 \\
$S J A$ & 47 & +33 & +21 & +51 \\
$S L$ & 75 & -33 & -23 & -35 \\
$S Y L$ & 89 & -36 & -12 & -26 \\
$L B$ & 70 & -2 & -2 & -21 \\
$L F$ & 33 & -33 & -40 & -36 \\
\hline
\end{tabular}

Table 3. Erythrocyte membrane ATPase activity assayed in presence of cystic fibrosis of the pancreas and control saliva

\begin{tabular}{|c|c|c|c|c|c|c|}
\hline \multicolumn{4}{|c|}{$\begin{array}{l}\text { Activity in presence of } \\
\text { patient saliva, nmol } \mathrm{P}_{\mathrm{i}} \\
\text { released } / \mathrm{mg} \text { dry wt } \\
\text { membrane suspension } / \mathrm{hr}\end{array}$} & \multicolumn{3}{|c|}{$\begin{array}{l}\text { Activity in presence of } \\
\text { control saliva, nmol } \mathrm{P}_{\mathrm{i}} \\
\text { released } / \mathrm{mg} \mathrm{dry} \mathrm{wt} \\
\text { membrane suspension } / \mathrm{hr}\end{array}$} \\
\hline $\begin{array}{c}\text { Expl. } \\
\text { no. }\end{array}$ & Total & $\begin{array}{l}\text { Ouabain } \\
\text { sensitive }\end{array}$ & $\begin{array}{l}\text { Ouabain } \\
\text { insensitive }\end{array}$ & Total & $\begin{array}{l}\text { Ouabain } \\
\text { sensitive }\end{array}$ & $\begin{array}{l}\text { Ouabain } \\
\text { insensitive }\end{array}$ \\
\hline 1 & 314 & 43 & 271 & 344 & 49 & 295 \\
\hline 2 & 94 & 59 & 35 & 172 & 80 & 92 \\
\hline 3 & 191 & 53 & 138 & 162 & 59 & 103 \\
\hline 4 & 75 & 26 & 49 & 78 & 38 & 40 \\
\hline 5 & 112 & 15 & 98 & 120 & 24 & 96 \\
\hline 6 & 35 & 9 & 26 & 56 & 10 & 46 \\
\hline 7 & 108 & 44 & 64 & 117 & 58 & 59 \\
\hline 8 & 160 & 65 & 94 & 149 & 46 & 104 \\
\hline 9 & 66 & 20 & 46 & 63 & 29 & 34 \\
\hline 10 & 70 & 11 & 59 & 18 & 13 & 5 \\
\hline
\end{tabular}

$16 \%$ as a result of the action of CFP saliva. This ratio was significantly different from 1.00 with a $P$ value $<0.05$ (Wilcoxon signed-rank test). In 9 out of the 10 experiments performed, the ouabain-sensitive component of ATPase activity was less in the presence of CFP saliva than it was in the presence of control saliva.

\section{DISCUSSION}

A factor in the saliva of children with CFP which inhibits $\mathrm{Na}$ transport in the rat parotid duct was first demonstrated by Mangos et al. (14). Other investigators have subsequently demonstrated this factor in submandibular, sublingual, and submucosal saliva, but not in parotid saliva (18). Attempts to establish the molecular pathogenesis of this inhibition have proved difficult. Mangos et al. were unable to demonstrate an effect on the in vitro activity of membrane ATPase preparations obtained from bovine parotid, human erythrocytes, and rat kidney. Such investigations have been hampered by the large amount of phosphorus in normal saliva, which is many times the small amount of phosphorus released from ATP in the usual ATPase assay. If saliva from children with CFP is added directly to an ATPase assay system, the high concentration of phosphorus present in the saliva makes it difficult to detect the small additional quantity of phosphorus released as a result of ATPase activity, and also may cause product inhibition of the ATPase reaction. In order to circumvent these problems, other investigators have diluted the saliva, or changed its composition by dialysis.

We chose a slightly different approach, incubating intact erythrocytes with undiluted saliva, and then measuring ATPase activity in the erythrocyte membranes after they had been washed free of saliva. CFP saliva caused a $26 \%$ decrease in the ouabain sensitive component of ATPase, relative to the action of control saliva. A second series of experiments, in which the phosphorus content of saliva was reduced by ultrafiltration, lent confirmation to these findings. In these experiments a reduction in ouabain-sensitive ATPase of $16 \%$ was effected.

From these latter experiments, it can be concluded that the ATPase inhibitory factor in CFP saliva has a molecular weight greater than 1,000, since this was the cutoff point of the ultrafiltration membrane which we employed. The observation of other investigators that such a factor is absent in dialyzed saliva (3) suggests that the substance is not bound to protein, and that the molecular weight is less than 10.000 . This corresponds to the molecular weight of a ciliotoxic factor isolated from the media of cultured fibroblasts of children with CFP. However, to date we have no further information on the molecular nature of the ATPase inhibitory factor. 
In a previous series of experiments, it was shown that the plasma of children with CFP also caused inhibition of erythrocyte membrane ouabain-sensitive ATPase. Kaiser et al. (10) have demonstrated a factor in the sweat of children with CFP which causes inhibition of net sodium transport in the sweat gland. It thus seems probable that there is a factor present in several body fluids of children with CFP which inhibits active Na transport. probably as a result of inhibition of a ouabain-sensitive component of ATPase.

The role of a calcium-activated component of ATPase in active calcium transport is less well established than the role of the ouabain-sensitive, sodium-potassium-activated ATPase in active sodium transport. Horton et al. (9) have demonstrated a decreased activity of this component of ATPase in the erythrocyte membrane of children with CFP, although other investigators have been unable to confirm this observation $(6,7)$.

Calcium is known to be elevated in the saliva of children with CFP. Active calcium reabsorption is believed to occur in the parotid duct (12), a process which may well be mediated by a calcium-activated component of ATPase. In the current study, saliva from children with CFP caused a $24 \%$ decrease in this component of ATPase. We were unable to check this finding in our second series of experiments, since there was sufficient calcium left after our wash procedure to activate this component of ATPase, and make the experiments invalid.

\section{SUMMARY AND CONCLUSIONS}

Two separate series of experiments were carried out to determine the effect of saliva from children with CFP on an ATP hydrolyzing enzyme system. In both series of experiments the CFP saliva brought about a significant decrease in the activity of the sodium-potassium-activated, ouabain-sensitive component of ATPase. In addition, in one series of experiments, CFP saliva resulted in a significant decrease in a calcium-activated component of ATPase.

We conclude from these experiments that there is a factor in the saliva of children with CFP which interferes with active cation transport as a result of inhibition of one or more components of the ATP hydrolyzing enzyme system.

\section{REFERENCES AND NOTES}

1. Balfe, J. W. Cole, C., and Welt, L. G.: Red cell transport defect in patients with cystic fibrosis and in their parents. Science, 162: 689 (1968).

2. Barnett, D. R. Kurosky, A., Bowman, B. H., Hutchison, F., Schmoyer, I., and Carson, S.D.: Cystic fibrosis: Molecular weight estimation of the ciliary inhibitor. Texas Rep. Biol. Med. 31: 703 (1973)

Copyright (C) 1975 International Pediatric Research Foundation, Inc.
3. Besley G.F.N and Patrick, A D - The effect of cystic fibrosis plasma and saliva on enzyme systems of cell membranes. Proceedings of the Fifth International Cystic Fibrosis Conference, p. 14 (Cystic Fibrosis Research Trust, London, 1969).

4. Cole, $\mathrm{C}, \mathrm{H}$, and Dirks, J $\mathrm{H}$. Changes in erythrocyte membrane ATPase in patients with cystic fibrosis of the pancreas. Pediat. Res., 6: 616 (1972).

3. Cole, C. H.: Decreased ouabain-sensitive adenosine triphosphatase activity in the erythrocyte membrane of patients with chronic renal disease. Clin. Sci. Mol. Med., 45: 775 (1973)

6. Duffy, M. J. Cohn, E. V., and Schwarz, V.: Ca ${ }^{2 \cdot}$ uptake and binding by isolated erythrocyte membranes from cystic fibrosis and control subjects. Clin. Chim. Acta, 50: 97 (1974).

7. Feig, S. A., Segal, G. B., Kern, K. A., Osher, A. B., and Schwartz, R. H. Erythrocyte transport function in cystic fibrosis. Pediat. Res.. 8: 594 (1974).

8. Hanahan, D. J and Ekholm, J. Changes in erythrocyte membranes during preparation, as expressed by ATPase activity. Biochem. Biophys. Acta, 255: $413(1972)$.

9. Horton. C. R., Cole, W. Q.. and Bader, H.: Decreased Ca transport ATPase in cystic fibrosis erythrocytes. Biochem. Biophys. Res. Commun., 40: 505 (1970).

10. Kaiser, D. Drack, E., and Rossi, E. Inhibition of net sodium transport in single sweat glands by sweat of patients with cystic fibrosis of the pancreas. Pediat. Res., 5: 167 (1971).

11. Katz, A. I., and Epstein, F. H.: Physiologic role of Na-K-activated ATPase in the transport of cations across biologic membranes. New Eng. J. Med., 278: 253 (1968).

12. Kreusser, W., Heidland, A., Hennemann, H., Wigand, M., and Krauf, H.: Mono and divalent electrolyte pattern, $\mathrm{pCO}_{2}$ and $\mathrm{pH}$ in relation to flow rate in normal human parotid saliva. Eur. J. Clin. Invest., 2: 398 (1972).

13. Lowry, $\mathrm{O} . \mathrm{H}$ and Lopez J. A. The determination of inorganic phosphate in the presence of labile phosphate esters. J. Biol. Chem.. 162: 421 (1946).

14. Mangos, J. A., McSherry, N. R., and Benke, P. J.: A sodium transport inhibitory factor in the saliva of patients with cystic fibrosis of the pancreas. Pediat. Res., 1: 436 (1967).

15. Schatzman, H. J., and Vincenzi, F. F.: Calcium movement across membrane of human red cells. J. Physiol. 201: 369 (1969).

16. Shwachman, H.: Long term study of 105 patients with cystic fibrosis. Amer. J Dis. Child., $96: 6$ (1958).

17. Spock, A., Heick, H. M. C., Cress, H., and Logan, W. S. : Abnormal serum factor in patients with cystic fibrosis of the pancreas. Pediat. Res., 1: 173 (1967).

18. Taylor, A., Mayo, J. W., Boat, F. F., and Matthews, L. W.: Standardized assay for the sodium reabsorption inhibitory effect and studies of its salivary gland distribution in patients with cystic fibrosis. Pediat. Res., 8: 861 (1974).

19. Wiesmann, U. N. Boat, T. F and DiSant Agnese, P. A.: Flow rates and electrolytes in minor salivary gland saliva in normal subjets and patients with cystic fibrosis. Lancet, $i i: 510$ (1972).

20. The use of human volunteers reported in this paper was reviewed by an ethics committee of McGill University and found acceptable. Informed consent was received from the parents of the children involved.

21. Grateful acknowledgment is made to Dr. Mimi Belmante for making available the patients who were used in this study

22. Dr. Cole is a Medical Research Council (Canada) Scholar.

23. Mr. Sella was supported by a summer student grant from the Canadian Cystic Fibrosis Foundation.

24. This research was supported by grants from the Canadian Cystic Fibrosis Foundation, and the Medical Research Council of Canada.

25. Requests for reprints should be addressed to: C. Cole, M.D., Department of Medicine, Royal Victoria Hospital, Montreal, Quebec, Canada. 26. Accepted for publication June 11, 1975. 